\title{
Análisis multielementales de secciones delgadas e interpretaciones preliminares en fragmentos de cerámica de Markaconga-Acomayo Cusco
}

\section{Multielemental analysis of thin sections and preliminary interpretations in ceramic fragments from Markaconga- Acomayo Cusco}

\author{
Wilber Bolívar Yapura \\ https://orcid.org/0000-0003-2089-4411 \\ Universidad Nacional de San Antonio Abad del Cusco \\ wilberbolivar@gmail.com \\ Gladys Lagos Aedo ( $†)$ \\ https://orcid.org/oooo-0003-2134-3208 \\ Universidad Nacional de San Antonio Abad del Cusco \\ gladysnro1@hotmail.com \\ Jorge Luis Gamarra Gamio \\ https://orcid.org/oooo-0002-9320-7013 \\ Dirección Desconcentrada de Cultura Cusco \\ jorgitoluisgamarrag@gmail.com
}

\section{RESUMEN}

Los análisis fisicoquímicos y multielementales, realizados en fragmentos cerámicos de superficie procedentes de Markaconga, ubicado en la provincia de Acomayo en Cusco, tuvo por objeto determinar la relación e interrelación en la composición química de las pastas de cerámica, pigmentos y engobes presentes en sus decoraciones, con la finalidad de identificar momentos de manufactura y/o transferencia cromática, simbológica y semiótica, presentes en estos fragmentos. El mismo que nos permite construir una interpretación preliminar, del grado de influencia y re- 
laciones con entidades tempranas emplazadas en la cuenca norte del Lago Titicaca, que tuvieron patrones estilísticos y artísticos identificables en su alfarería.

Palabras clave: Cerámica Markaconga; pasta; pigmentos; fluorescencia de Rayos X.

\section{ABSTRACT}

The Physicochemical and multielemental analyzes, carried out on ceramic surface fragments from Markaconga, located in the province of Acomayo in Cusco, aimed to determine the relationship and interrelation in the chemical composition of ceramic pastes, pigments and slips present in its decorations, in order to identify moments of manufacture and/or chromatic, symbolic and semiotic transfer, present in these fragments. The same one that allows us to build a preliminary interpretation of the degree of influence and relationships from early societies of the North basin of Lake Titicaca, which had very identifiable stylistic and artistic patterns in their pottery.

Keywords: Markaconga ceramics; paste; pigments; X-ray fluorescence.

ReCibidO: 14/09/2020 - ACEPTADO: 20/11/2020 - PublicAdO: 25/06/2021

\section{INTRODUCCIÓN}

Este trabajo nace como fruto del curso de Petrografía de cerámica para arqueólogos, ofrecida por la universidad de Yale (USA), en el mes de agosto del 2016, cuya experiencia nos sirvió para hacer una exploración sobre la variabilidad petrográfica en muestras en fragmentos de cerámica superficial provenientes del poblado de Markaconga, con el propósito de introducirnos en el uso de materiales mineralógicos y otros para la manufactura de cerámica, durante el horizonte temprano en esta área.

Jiménez-Bodillo (2017) manifiesta que en los últimos años la arqueología ha ampliado su potencial para ofrecer explicaciones acerca del pasado, gracias a la discusión de los fundamentos epistemológicos y la incorporación de nuevos métodos de observación (e.g. arqueometría, etnoarqueología, etc.). Esto, ha aumentado nuestra capacidad de análisis y práctica cotidiana la cual se ha visto beneficiada con el uso de la informática y tecnologías de comunicación. La utilización de ordenadores (inicialmente de escritorio y laptops muy versátiles) nos han permitido sistematizar, clasificar y consultar datos rápida y eficientemente, así como forjar nuevas clases de información novedosos como los modelos tridimensionales de sitios y artefactos ubicados en ambientes virtuales y contextualizados con información multimedia por medio de la tecnología de realidad aumentada (p.11).

Fernández Martínez (2015) en su interrogante ¿Por qué necesitamos la estadística? anota una inscripción de la fachada de la Escuela de Investigación de la Univer- 
sidad de Chicago una frase de William Thomson, lord Kelvin "Si no puedes medir, tu conocimiento es escaso e insatisfactorio". Por esto la arqueología introduce como necesidad los tratamientos o enfoques cuantitavos, para analizar los restos materiales de la actividad humana del pasado. En el instante que iniciamos a analizar y describir los objetos es cuando pasamos a tener datos sobre ellos, en nuestro caso son los fragmentos de cerámica, en ellos estudiaremos el tipo de arcilla, color, dureza, forma de vasija, decoración, dimensiones, peso, etc. (pp. 7-29).

Druc y Chávez (2014), nos advierten que el uso de nuevos microscopios digitales de mano ha cambiado drásticamente en el estudio preliminar de los fragmentos de cerámicas prehispánicas, además nos admite establecer tipologías, agrupamiento de pastas mineralógicas y texturas similares, consintiendo elegir muestras para un análisis petrográfico o químico detallado. De igual modo nos permite una adecuada aproximación de los diferentes grupos de pastas en una colección, las técnicas de manufactura y materias primas posiblemente utilizadas por el alfarero. ${ }^{1}$ Las investigadoras alcanzan un manual en la que facilitan el trabajo de los arqueólogos para iniciar estudios ceramológicos. Tal como lo sugieren, las descripciones llevan informaciones que ayudan a reconocer un mineral de otro, o ciertas técnicas de elaboración de vasijas; introduciéndose nociones de granulometría, textura y tecnología cerámica, vinculados con la producción alfarera.

Una cerámica resulta de los conocimientos en la selección de las materias primas por el alfarero, su preparación, mezcla, manufactura y quema, que alteran el estado original de los materiales utilizados. Los minerales y las rocas en el presente estudio, presentan inclusiones que se encuentran comúnmente en muchas pastas cerámicas. Sin embargo, estos dan testimonio de solo una parte de la variabilidad composicional observada en las cerámicas prehispánica de Markaconga. Esta variabilidad depende de la geología existente en las cercanías de los lugares de las minas, producción y de prácticas de los ceramistas, en cuanto a la elección de materias primas utilizadas y al modo de preparación de la pasta (pp. 7-8).

Sobre las contribuciones analíticas podemos manifestar, que esta propuesta de sistematización de análisis químico por fluorescencia de rayos $\mathrm{X}$ de pastas y pigmentos de cerámica o multielementales, es la primera y la realizamos a fragmentos de cerámica de superficie (06 muestras) en el año 2013; mostrándonos un corpus iconográfico Pukara, Qeya, Tiwanaku, Wari y estilos locales (Marcavalle y Chanapata). Este estudio piloto diseñado para averiguar si un análisis multielemental utilizando cortes de secciones delgadas son suficientes para identificar las diferencias entre intercambio y emulación de cerámica.

1. Alfarero debe entenderse en un sentido general, sin presupuesto de género, incluyendo hombres y mujeres involucrados en la producción de cerámica, según Druc y Chávez (2014). 
Lo que deseamos confirmar con el resultado, es la idea de un contacto importante entre las culturas tempranas de la zona norte del Titicaca hacia el Cuzco, que continúa en el Intermedio Temprano, como un nódulo de interacción entre el altiplano representado por Tiwanaku y culturas locales en la zona de Markaconga, para el Horizonte Medio esta área se convierte en una frontera de interacción entre entidades locales, los Tiwanaku y Wari.

\section{CONTEXTO GEOGRÁFICO}

El centro poblado de Markaconga, se localiza a $105 \mathrm{~km}$ de la vía asfaltada Cusco-Acomayo, el desvío se inicia en el puente Chuquicahuana sobre el río Vilcanota, en el distrito de Sangarara, provincia de Acomayo, región del Cusco, al oeste de la laguna de Pomacanchi, de acuerdo al sistema de posicionamiento global está en las coordenadas 19L 0222937 UTM 8453338 y a una altura de 3,661 rodeado por los Apus Uchucumpay y Pukarani. Mayhua (1994) sostiene que políticamente el distrito de Sangarará está constituido por el poblado de Markaconga, ${ }^{2}$ con las siguientes comunidades de Yanampampa, Chahuay, Chilchicaya y sus límites son:

- Por el Norte con el Distrito de Cusipata (Quispicanchi).

- Por el Sur con el Distrito de Pomacanchi (Acomayo).

- Por el Este con el Distrito de Acopia (Acomayo).

- Por el Oeste con el Distrito de Acomayo.

Toponimia: Por testimonio de los pobladores señalan que el nombre de Sangarará proviene de una planta nativa que abunda en el lugar. De acuerdo a la composición gramatical proviene de Saqarara = planta nativa. ${ }^{3}$ Otra versión señala que el nombre de Markaconga donde se encontraban asentados varios ayllus, habrían adquirido el nombre debido a razón de los constantes abusos por parte de los conquistadores, surgiendo así el caudillo Martín Llanquetayña, quien al haber sido objeto de represión, habría sido herido en el cuello, obteniendo desde entonces el nombre de "maracongas" (marcacuncas y/o cuellos marcados). ${ }^{4}$ Interpretación que es corroborado por Tito Llerena Delgado (Alcalde), ${ }^{5}$ de acuerdo a la Academia de la Lengua Quéchua, Markaconga deriva de los vocablos marka que significa casa y kunka = cuello siendo su acepción gramatical atribuyendo como "lugar estrecho".

2.Actualmente, el centro poblado de Markaconga está compuesto por los barrios de Tayña, Qollana, Llullupata, y Hahuay; dicha conformación correspondería a la organización de los ayllus y comunidades, que se habrían asentado en esta zona, conservando a la fecha un sistema de organización social. www.Mapa del distrito de Markaconga en el distrito de Sangarará de Acomayo del Banco de información distrital del INEI (Instituto Nacional de Estadística e informática 2013).

3. Informe oral de Herbert Luna Fernández alcalde de la Municipalidad Distrital de Sangarará, 2005.

4. Héctor Espinoza Martínez. Proyecto de Investigación Arqueológica de Kullupata, 2012.

5. Tito Llerena Delgado. Entrevista en la Localidad de Markaconga en el año 2013. 


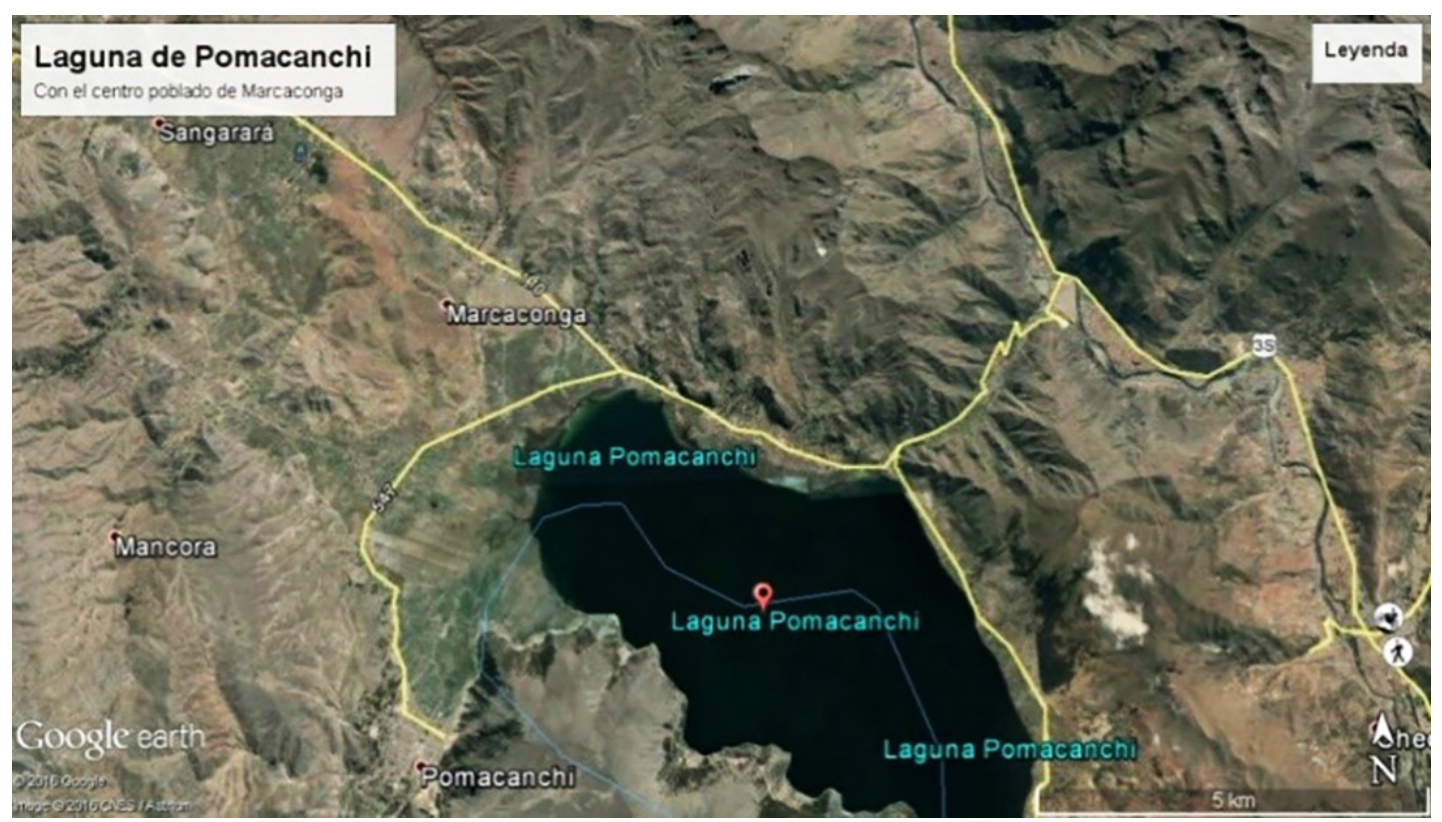

Figura 01. Fuente: Google earth 2016

Medio geográfico: Su formación geográfica corresponde a una explanada que concierne a las orillas del lago Pomacanchi, en el cual se ha desarrollado planicies que tocan a nichos ecológicos de tipo Suni a Puna (3700 a 4000 m s. n. m.).

Su formación orogénica describe un terreno de pendiente regular a horizontal, cuya estructura está conformada por una base de rocosa, con algunos afloramientos rocosos de rocas calcáreas que sobresalen a superficie, su cobertura de suelos corresponde a sedimentos de suelos arcillosos y poco arenosos de color marrón con contenido de cantos rodados de tamaños variados con potencias profundas. Ostenta ríos que atraviesan la zona formando así los pequeños y estrechos valles donde se asienta la población.

Su orografía corresponde a pequeños cerros que se elevan alrededor del lago y que forman ciertas quebradas donde se asientan los poblados. La población alcanza a 300 familias aproximadamente y a un total de 1500 habitantes, en los que se puede observar mayor cantidad de gente joven, su producción agropecuaria se limita a la siembra y cosecha de papa, olluco, habas, cebada y algunos animales menores. Adicionalmente se dedican a la pesca proveniente del lago. Cuenta con servicios de primera necesidad como son, agua potable y electrificación, centros educativos: inicial, primaria y secundaria; posta médica, locales comunales y campo deportivo.

Se encuentra al sur de la región del Cusco y forma la parte norte del nudo del Vilcanota de la cordillera de los Andes. 
Clima: es de dos estaciones bien definidas.

a) Invierno Seco y frío: Empieza el mes de mayo se prolonga hasta octubre con temperaturas de $-20^{\circ} \mathrm{C}$ a $2^{\circ} \mathrm{C}$, de fuertes helados en las noches.

b) Verano Húmedo: Se inicia en noviembre, diciembre y se prolonga hasta los meses enero, febrero y mediados de abril, se presenta las precipitaciones pluviales y la humedad se incrementa. La humedad relativa supera el 40\%, mientras la precipitación anual supera los $700 \mathrm{~mm}$.

Piso ecológico: Por la altitud se ubica dentro de la división vertical de los andes, corresponde al piso de "puna". Su vegetación, el clima, la temperatura anual y la fauna que habita en la zona lo demuestran.

Flora: La flora de mayor cobertura que abunda, son la familia de las gramíneas o el ichu andino en una gama de más de seis variedades. Las eritrinas, altricarios, cactus. Los cultivables avena forrajera, ray gras, alfalfa, trébol.

Fauna: En lo que respecta a la fauna silvestre; por la actividad de los pobladores la se ausentó. De los mamíferos sobreviven : taruca, zorro, ratón, zorrino, gato del pajonal, vicuña. Domesticados: Caballo, asnos, vacunos, ovejas, perro, gato.

Aves: Lequecho, patos cordilleranos, aguilucho, cernícalos, picaflor, gorriones, alqamari, cóndor, gaviota, golondrina.

Medios de subsistencia: El mayor medio de la subsistencia del poblador es el pastoreo de sus ganados como: llamas, ovejas, ganado vacuno, que gran parte de las familias las realizan; a ello se añaden los caballos y el asno, como fuerza de transporte o carga.

Agricultura: Se dedican al cultivo de plantas alimenticias en pequeñas parcelas, exclusivamente para el consumo familiar. Lo realizan en canchas que utilizan como corral de sus ganados y en lugares estratégicos que ellos lo mantienen para tal propósito. Las especies que cultivan son: quinua, qañiwa, oca, olluco, añu, papa amarga, mallku papa o araq papa.

Sobre la cerámica: Para entender los análisis estilísticos de la cerámica por parte de los arqueólogos, siempre hace falta información básica que nos ayude a aclarar las características de las cerámicas, desde el punto de vista de las materias primas y la tecnología utilizada por los alfareros, cuyos recipientes generalmente suelen ser frágiles mas no sus fragmentos.

Estas materias primas y la tecnología de manufactura no son fáciles de percibir sin estudios y análisis detallados. Puesto que el objetivo es determinar la relación e interrelación de la composición química de las pastas de cerámica, pigmentos y engobes presentes en sus decoraciones a fin de identificar momentos de manufactura y/o transferencia cromática, simbológica y semiótica presentes en los fragmentos cerámicos. 
El proceso en manufactura de ceramios está constituido por una continuidad de acciones que son el resultado de elecciones técnicas y específicas, las cuales acatan en gran medida los conocimientos y la experiencia del alfarero. Cada elección técnica tiene un efecto concreto sobre las propiedades de los objetos, como por ejemplo la porosidad, la resistencia del material cerámico al estrés térmico, y la eficacia calorífica.

\section{METODOLOGÍA}

Los métodos arqueométricos como elemento auxiliar de la arqueología, nos permiten los usos de métodos físicos, químicos e instrumentales, para analizar, caracterizar e interpretar los resultados que proceden de fragmentos cerámicos recuperados de superficie en el poblado de Markaconga. Luego estos resultados sirvieron como base comparativa, para un trabajo más amplio de fragmentos de cerámica y otro hallazgos recuperados a través de una arqueología de rescate ${ }^{6}$ en la calle Tayña (Belaunde) de la misma localidad, que estuvo asociada con metales, huesos, elementos malacológicos y ceramios, que formaran parte de otro trabajo.

Para las primeras imágenes utilizamos el microscopio Digital Dino-Lite, que tiene la aplicación Dino Capture 2.0, luego para los análisis fisicoquímicos se utilizó instrumental microscópico (microscopio STEREO DISCOVERY V8) (microscopio para contraste de fases de luz polarizada AXIO IMAGER 22m), analizador de fluorescencia de rayos X (NITON XL3 GOLDD). La metodología vigente para la petrografía cerámica puede aplicarse al análisis de las pastas frescas a fin de determinar la composición mineral granulometría, angulosidad, distribución y orientación de las inclusiones que define el perfil composicional.

\section{ANÁLISIS DE LAS PASTAS DE CERÁMICA POR MUESTRAS DE MARKACONGA}

(Figuras 01 y 02)
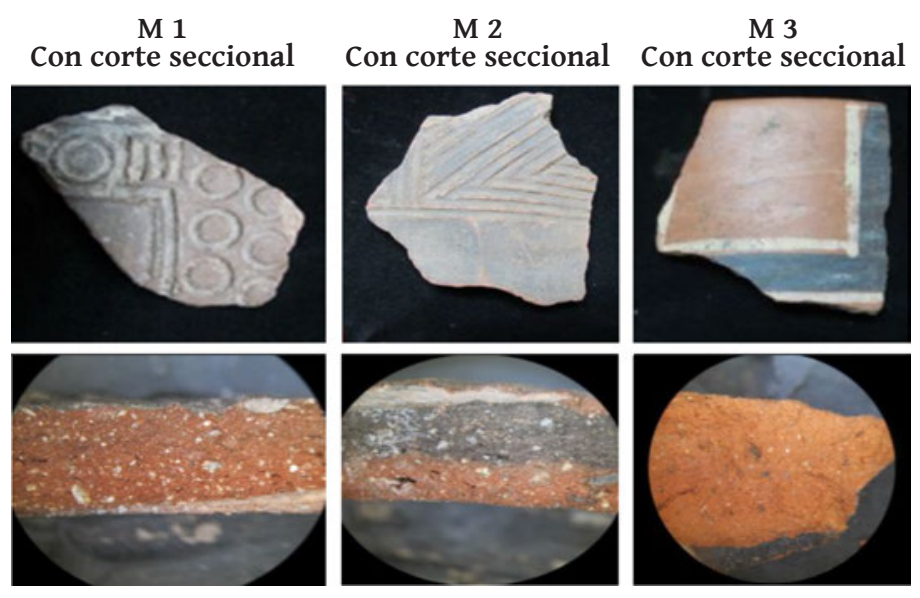

Figura 01

6. Colección Markaconga, recuperados por Wilber Bolívar Yapura, Rene Pilco y Antonio Terrazas Jiménez en el 2006 mediante rescate arqueológico, en trabajos de obra pública en el centro poblado de Markaconga. 

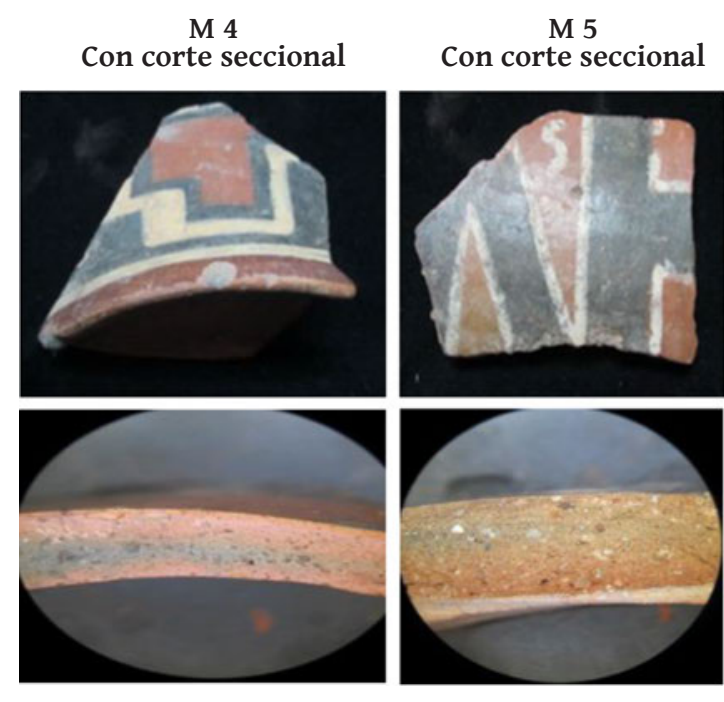

M 6

Con corte seccional

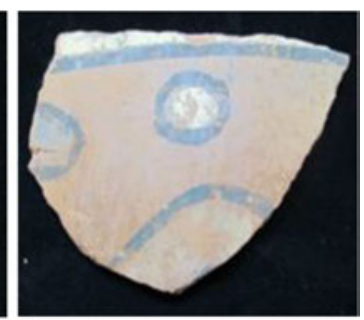

Figura 02

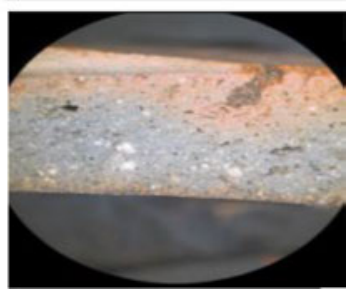

Muestra 1: Las inclusiones plásticas nos indican el contenido de cuarzo y feldespatos policristalinos angulosos cuyo diámetro promedio es de $0.994 \mathrm{~mm}$ en su granulometría, su textura es muy tosca (Wentworth). Su color según la guía Munsell: 5 YR 4/2 (marrón rojizo). La densidad de área es 40.616 \% (ver figura 03).
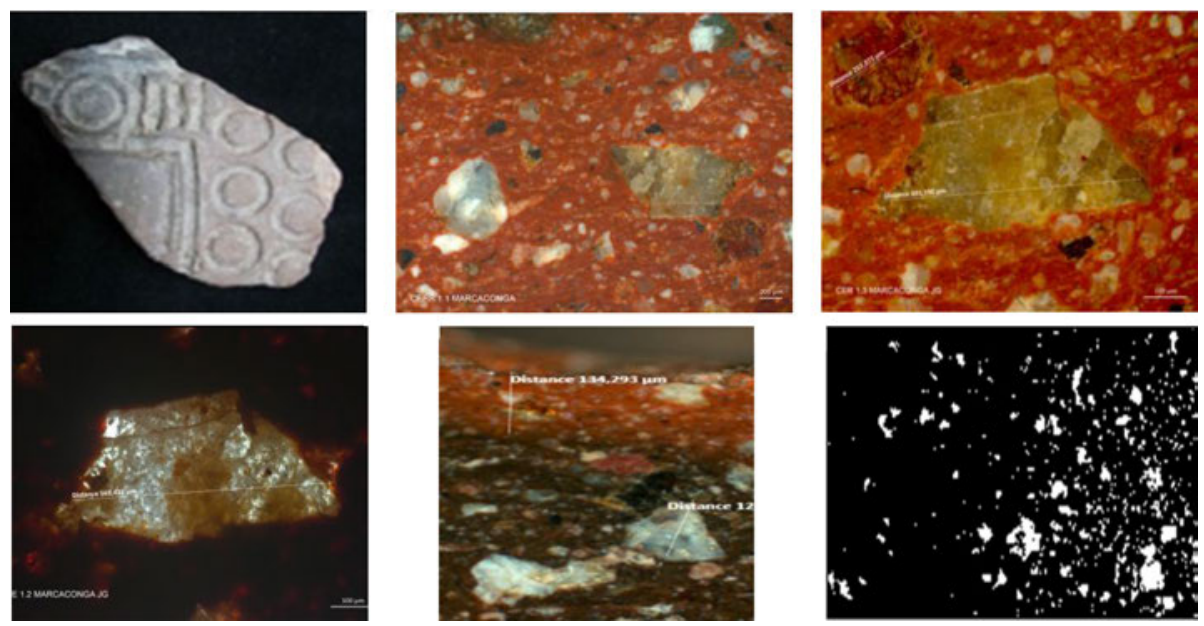

Figura 03

Muestra 2 (Cuarcita): Contiene cuarzos angulosos y subangulosos de tamaño mediano, y forman parte del sedimento piroclástico; tiene la forma redondeada de $1.167 \mathrm{~mm}$, de textura muy tosca. El color según la guía Munsell es de 5 YR 5/4 (marón rojizo), y tiene una densidad de 95.68.6 \% (ver figura 04). 

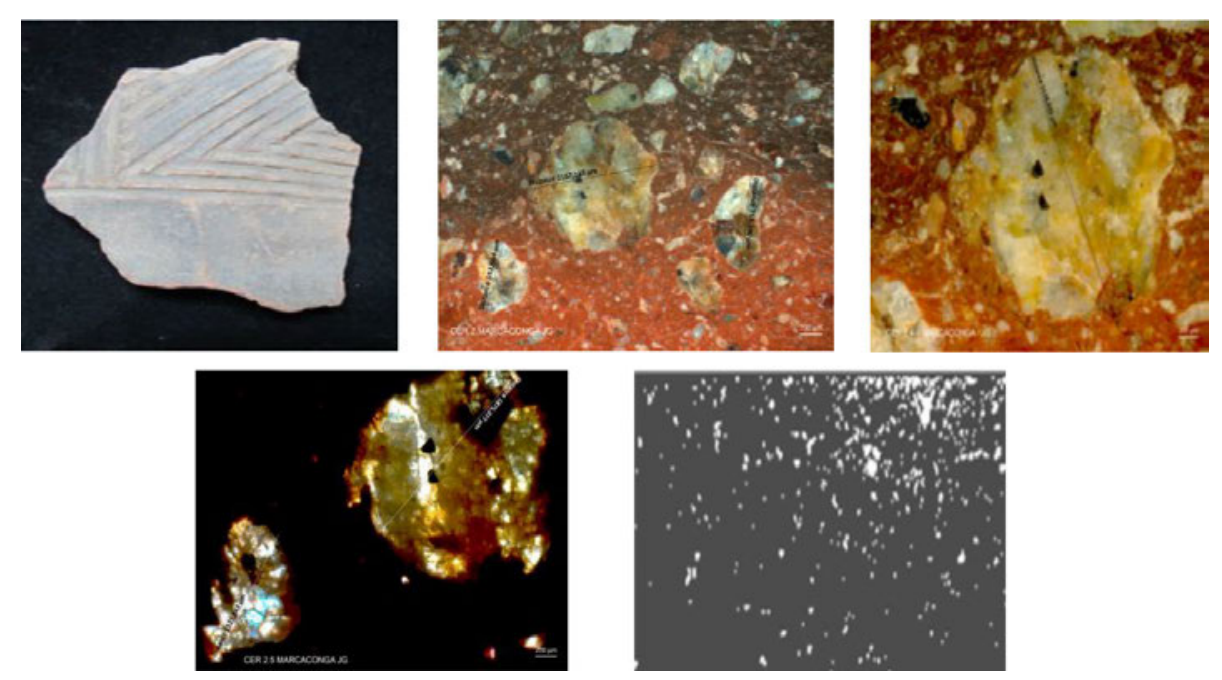

Figura 04

Muestra 3: Con minerales máficos muy pequeños de forma subangular. Tiene una composición mayoritaria de naturaleza félsica de $0.4124 \mathrm{~mm}$ de grano mediano. Se observa cristales azules de anfíboles, biotita y plagioclasas. Sus colores según la guía Munsell son: 2.5YR 5/6 (rojo); 5 YR 3/1(negro) (ver figura 05).
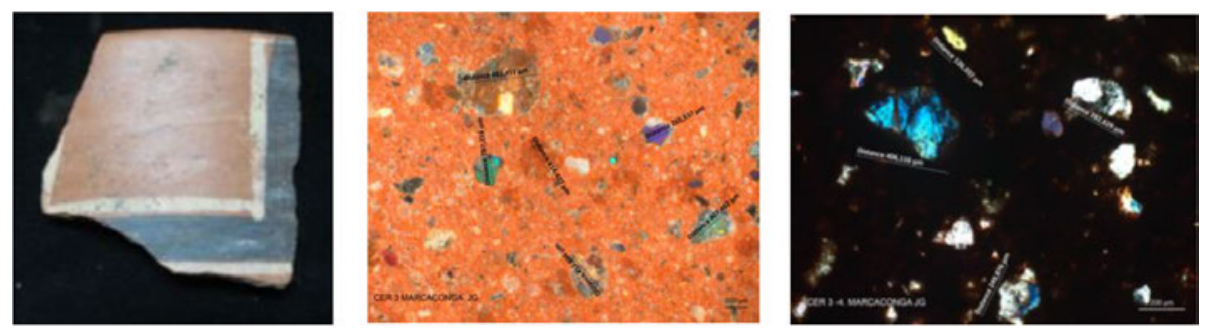

Figura 05

Muestra 4: Con una granulometría fina de $0.378 \mathrm{~mm}$, de granos subangulosos, con minerales félsicos policristalinos. Sus colores según la guía Munsell son: 2.5 YR 5/4 (rojo), 5 YR 3/1 (negro) (ver figura 06).
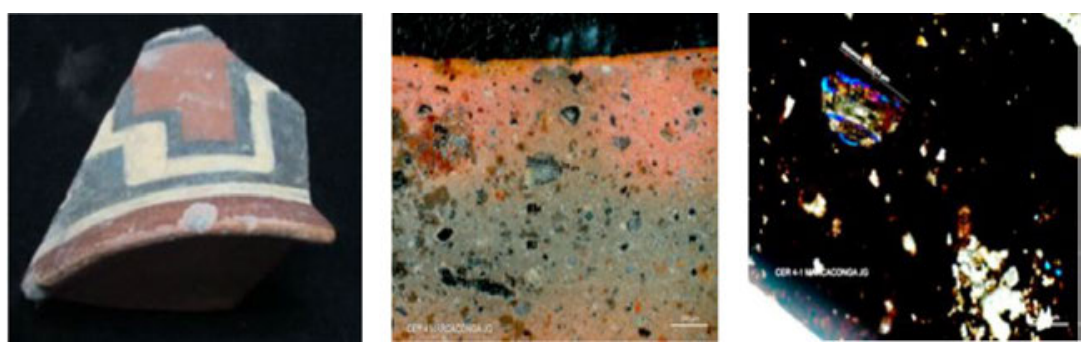

Figura 06 
Muestra 5: Su granulometría es de $0.147 \mathrm{~mm}$ muy fino. Su color según Munsell es 2.5 YR 5/4 (rojo), 5 YR 3/1 (negro). La petrografía muestra granos de feldespato con inclusiones de biotita de clastos subangulosos (ver figura 07).
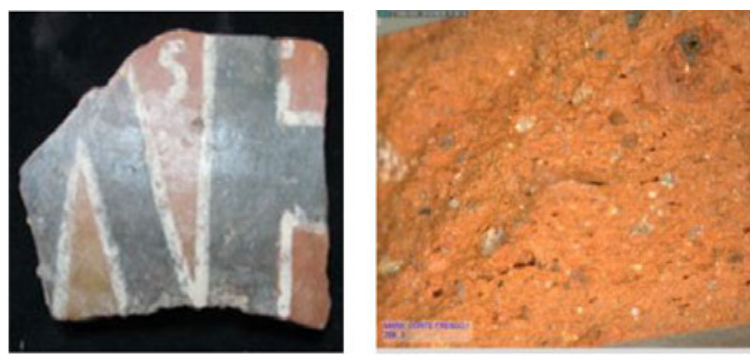

Figura 07

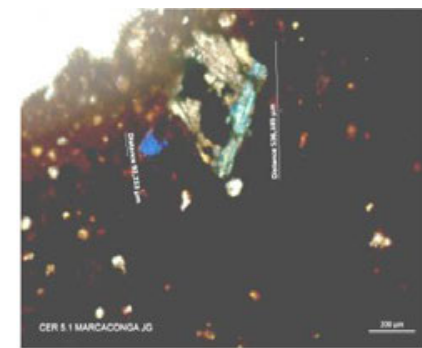

$\underline{m-2}$

Muestra 6: $0.368 \mathrm{~mm}$ de granulometría, fino. Su color según Munsell es 10 R 5/6 (rojo). Área: el 43.356\% considera inclusiones de elementos malacológicos molidos e incorporados a la pasta cerámica (ver figura 08).
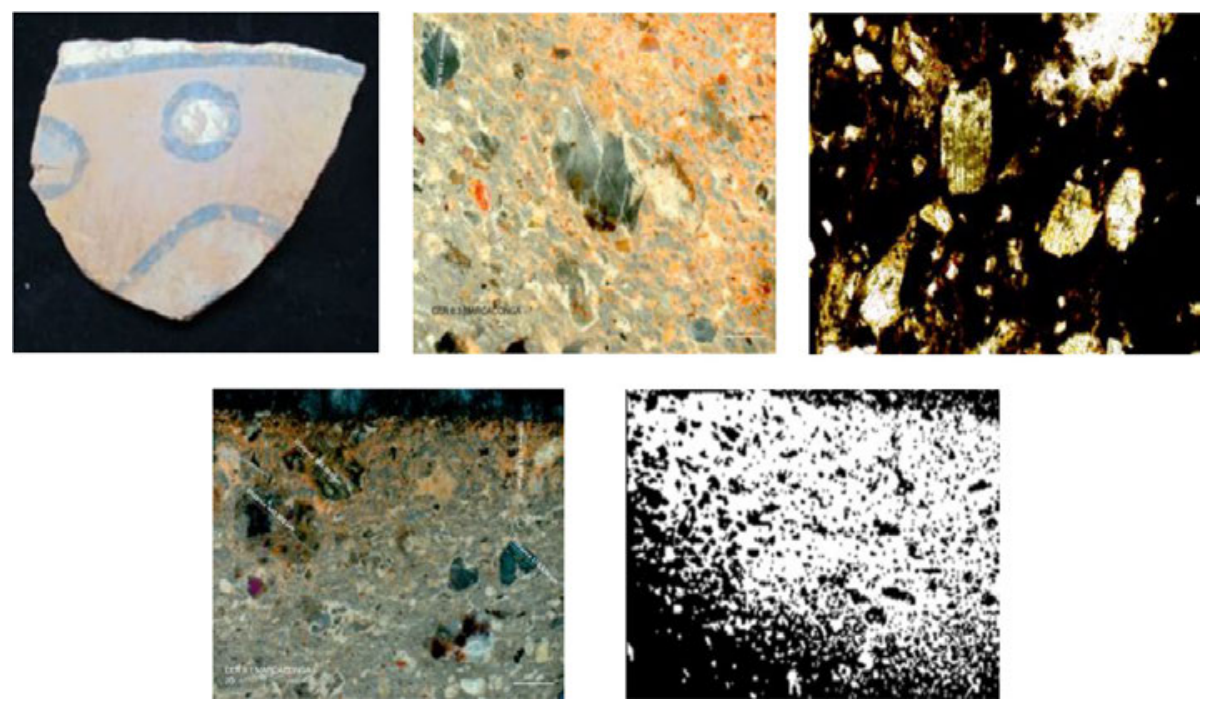

Figura 08

Los análisis en la granulometría de las inclusiones no plásticas nos muestran lo siguiente:

Los fragmentos de las muestras M1 y M2 tienen la granulometría de la inclusión no plástica, que van de la tosca a la muy tosca, en cambio los fragmentos de las muestras M3 y M4 tienen granulometrías finas, mientras que el fragmento de la muestra M5 es muy fino, finalmente la muestra M6 es fina de acuerdo a la escala de Wentworth. ${ }^{7}$ 
La evaluación granulométrica, muestra cierta similitud los fragmentos de las muestras M3 y M4 que difieren entre sí de los otros fragmentos de las muestras M1, M2, M5 y M6. Estos se expresan en los cuadros adjuntos (ver Tabla 1 y Gráfico 1).

Tabla 1

\begin{tabular}{|c|c|l|}
\hline MUESTRA & DP & Textura \\
\hline cer1 & 0.994 & tosco \\
\hline cer2 & 1.167 & muy tosco \\
\hline cer3 & 0.412412 & medio \\
\hline cer4 & 0.378 & fino \\
\hline cer5 & 0.147 & muy fino \\
\hline cer6 & 0.368 & fino \\
\hline
\end{tabular}

\section{Gráfico 1}

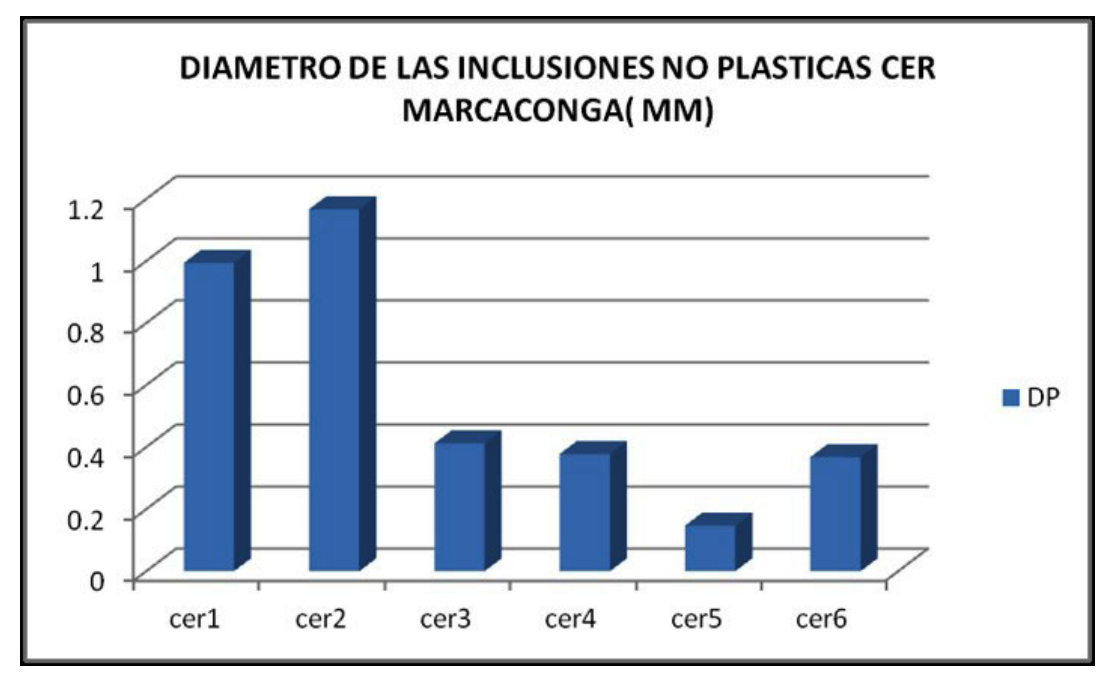

\section{Resultados de los análisis multielementales por fluorescencia de rayos X (FRX)}

Los resultados cuantitativos nos muestran la composición de los elementos químicos mayores expresado en partes por millón (Tabla 2).

Las muestras de los fragmentos M1 y M2 tienen similar composición química en los componentes de la pasta a nivel de elementos mayores (Gráfico 1); así como similar

7. Se tienen en uso varias escalas granulométricas, pero la de Udden-Wentworth (escala de Wentworth) es la más utilizada en geología. Esta Escala fue adoptada internacionalmente para la clasificación granulométrica de partículas sedimentarias. Fue propuesta en 1922 por C. K. Wentworth, basándose en la anterior escala de J. A. Udden, de 1898. Parte de 1 mm y, dividiendo o multiplicando por 2, en sentido decreciente o creciente de tamaño respectivamente, se definen los límites de diámetro de cada clase, desde partículas de tamaño arcilla (con diámetro menor de 1/256 mm) a bloques (con diámetro mayor de $256 \mathrm{~mm}$ ). Fue propuesta en 1922 por C. K. Wentworth, basándose en la anterior escala de J. A. Udden, de 1898. 
composición se observa en los fragmentos de las muestras M5 y M6, que luego de compararlas con la composición de la arcilla local no muestra que existan diferencias composicionales entre sí (Gráfico 2).

Los análisis por FRX utilizado para analizar los componentes químicos de cada una de las pastas, nos muestra que existen diferencias composicionales entre sus componentes expresados a nivel de unidades mineralógicas y óxidos de silicio, aluminio y feldespato, también se hallan estas diferencias tanto en los componentes mineralógicos como en el contenido de las inclusiones no plásticas expresado en \% por peso, composición química de las pastas a nivel mineralógico (Tabla 3 y Gráfico 3).

Tabla 2

\begin{tabular}{|c|c|c|c|c|}
\hline \multirow{2}{*}{ MUESTRAS } & \multicolumn{4}{|c|}{ PPM } \\
\cline { 2 - 5 } & $\mathrm{Si}$ & $\mathrm{Al}$ & $\mathrm{Fe}$ & $\mathrm{Ca}$ \\
\hline cer $1 \mathrm{mcg}$ & 235983,47 & 68767,35 & 44763,93 & 22952,93 \\
\hline cer $2 \mathrm{mcg}$ & 227564,02 & 70016,26 & 46535,65 & 22627,42 \\
\hline cer $3 \mathrm{mcg}$ & 259457,97 & 67553,19 & 48071,98 & 6566,8 \\
\hline cer $4 \mathrm{mcg}$ & 244095,09 & 70317,17 & 48098,26 & 5682,31 \\
\hline cer $5 \mathrm{mcg}$ & 237319,64 & 64494,43 & 44026,57 & 24734,65 \\
\hline cer $6 \mathrm{mcg}$ & 241049,27 & 78086,18 & 45773,8 & 10512,73 \\
\hline
\end{tabular}

Gráfico 2

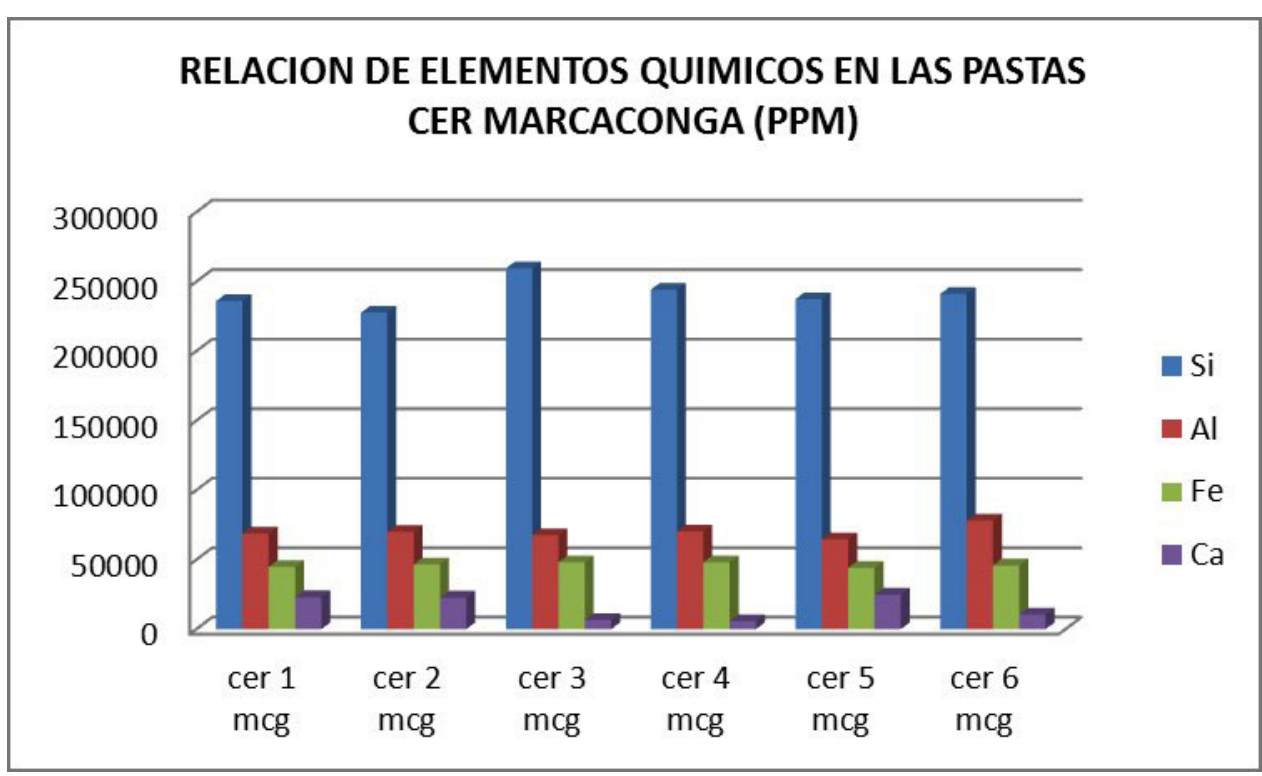


Tabla 3

\begin{tabular}{|l|r|r|r|r|r|r|r|r|}
\hline \multirow{2}{*}{ Componente } & \multicolumn{1}{|l|}{ cer1 } & \multicolumn{1}{l|}{ cer 2 } & \multicolumn{1}{l|}{ cer3 } & \multicolumn{1}{l|}{ cer5 } & \multicolumn{1}{l|}{ cer6 } & Arc Local \\
\cline { 2 - 8 } & \multicolumn{7}{|c|}{ \% } \\
\hline Cuarzo & 40.290492 & 37.1260516 & 43.6184177 & 40.3765909 & 41.8423599 & 42.7477138 & 31.7084746 \\
\hline Arcilla & 38.0108488 & 37.435857 & 34.8499456 & 37.1281195 & 35.4394082 & 36.2062198 & 36.4414783 \\
\hline Feldespato & 9.55244886 & 10.4760839 & 10.4041422 & 10.5363982 & 10.145287 & 10.3648032 & 10.0923616 \\
\hline Fe2O3 & 6.68704855 & 7.33362541 & 7.28326373 & 7.3799903 & 7.75893084 & 7.54314573 & 7.06500639 \\
\hline $\mathrm{MgO}$ & 0 & 1.27199826 & 1.44537426 & 2.36567446 & 2.4871448 & 0 & 2.62833526 \\
\hline $\mathrm{CaO}$ & 3.36478589 & 3.49402544 & 0.97497066 & 0.85413182 & 0.89798894 & 1.63956336 & 11.1486009 \\
\hline $\mathrm{P} 2 \mathrm{O} 5$ & 1.22564239 & 2.05190675 & 0.44939737 & 0.4575701 & 0.48106496 & 0.67907951 & 0.11470738 \\
\hline $\mathrm{MnO2}$ & 0.18221787 & 0.08900762 & 0.13589367 & 0.18485406 & 0.19434577 & 0.13668622 & 0.13269715 \\
\hline $\mathrm{TiO} 2$ & 0.68651559 & 0.72144402 & 0.83859472 & 0.71667073 & 0.75346964 & 0.68278835 & 0.66833829 \\
\hline
\end{tabular}

\begin{tabular}{|l|l|l|l|l|l|l|l|}
\hline Componente & cer1 & cer 2 & cer3 & cer4 & cer5 & cer6 & Arc Local \\
\hline Antiplástico & 49.8429409 & 47.6021355 & 54.0225599 & 50.912989 & 51.9876469 & 51.9876469 & 41.8008362 \\
\hline Plástico & 49.4705435 & 51.6764204 & 45.1388453 & 48.3703402 & 47.2588835 & 47.2588835 & 57.5308255 \\
\hline
\end{tabular}

\section{Gráfico 3}

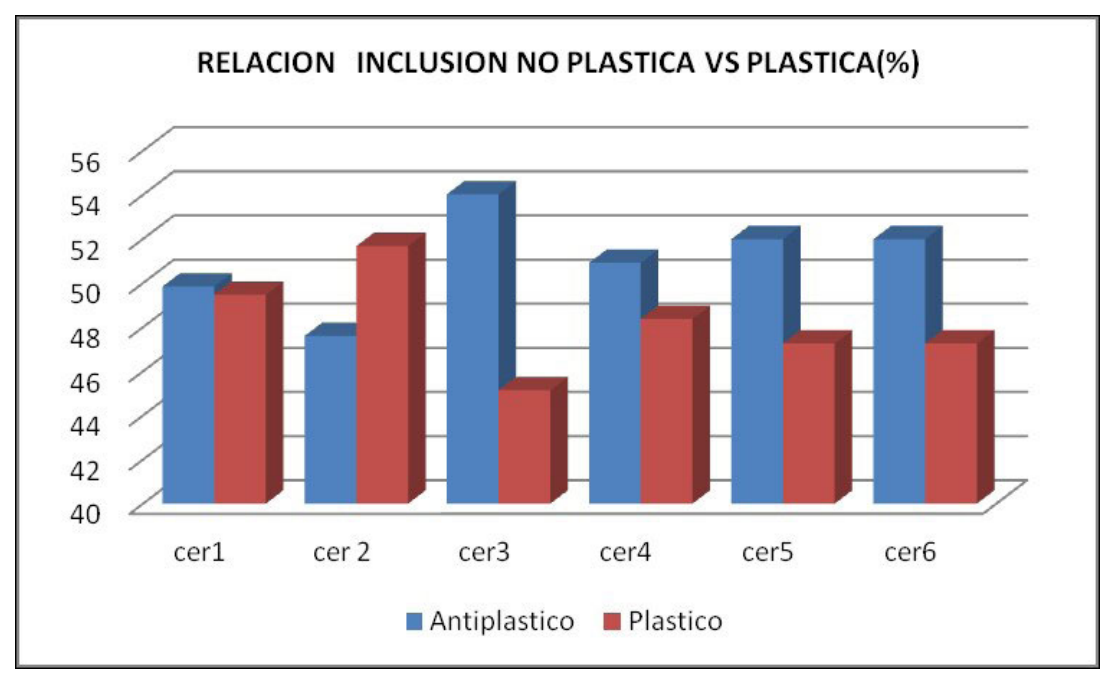

Los resultados expresados en la relación plástico y antiplástico en cada una de las muestras, nos indica que los fragmentos de las muestras M1 y M2 tienen distinta composición; así como las muestras M3 y M4, son distintos entre sí; pero los fragmentos de las muestras M5 y M6, corresponden a la misma pasta cerámica, pero con distinta decoración en su superficie.

A efectos de comprobar esta relación a nivel de elementos químicos menores, se realizó el análisis particular de los elementos de traza, a fin de evidenciar de mejor 
manera esta relación de confluencia de posibles materiales utilizados en la manufactura de cada uno de estos artefactos cerámicos, mediante la relación rubidio/ estroncio mostrando que las muestras de los fragmentos M1 y M2 en lo que concierne a los materiales utilizados para su fabricación proceden de una misma área, sin embrago los fragmentos de las muestras M3 y M4 proceden de otra fuente, mientras que los fragmentos de las muestras M5 y M6 también proceden de otra fuente, es decir estaríamos hablando de cuatro fuentes o canteras distintas en el grupo analizado (Gráfico 4).

Óxidos en engobes negros: El análisis de los engobes negros nos muestra similar contenido a nivel de óxidos entre las muestras M3 y M4, y diferencias entre las muestras M1 y M2, el engobe de la muestra M5 es diferente al engobe de la muestra M6 (Gráfico 5 y Tabla 4).

Óxidos en engobe rojo: Se muestra que los engobes rojos y naranja de las muestras M5 y M6 son similares (Gráfico 6 y Tabla 5).

Óxidos en engobe blanco/amarillo: El engobe amarillo de la muestra M3 es similar al engobe de la muestra M4 y distintos de la M3 y M6 (Gráfico 7 y Tabla 6).

\section{Gráfico 4}

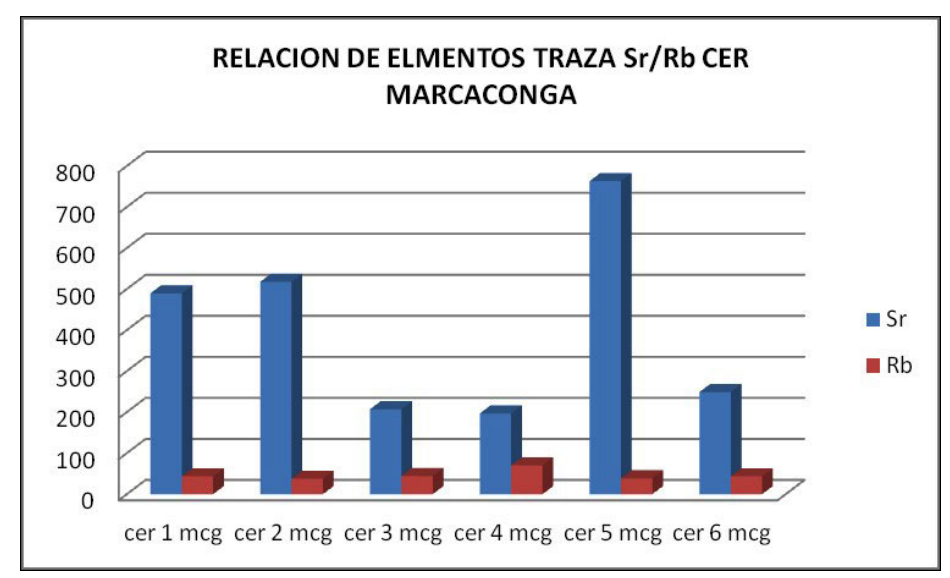

Relación de óxidos entre los engobes (figura 09)

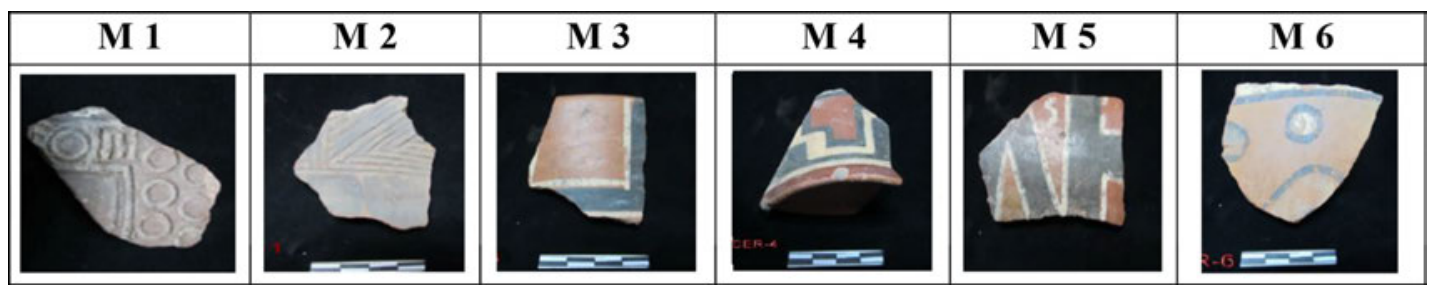


Gráfico 5

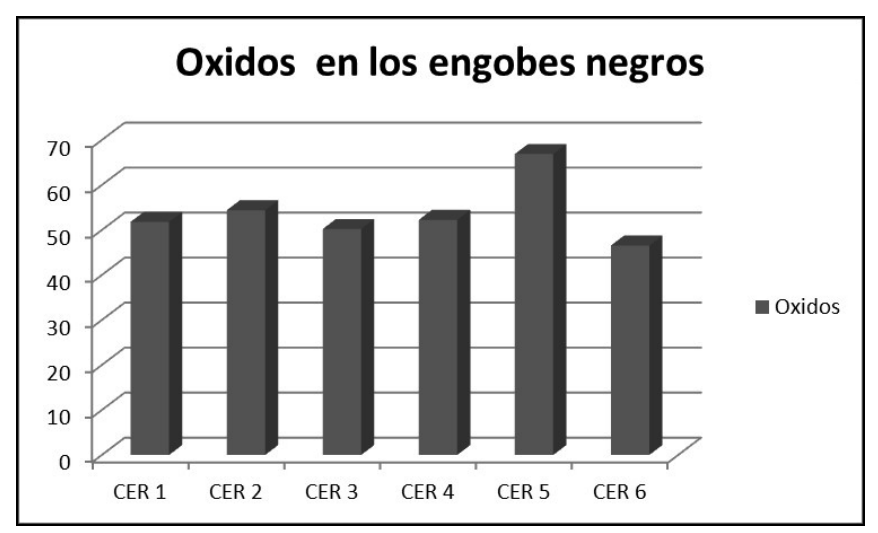

Gráfico 6

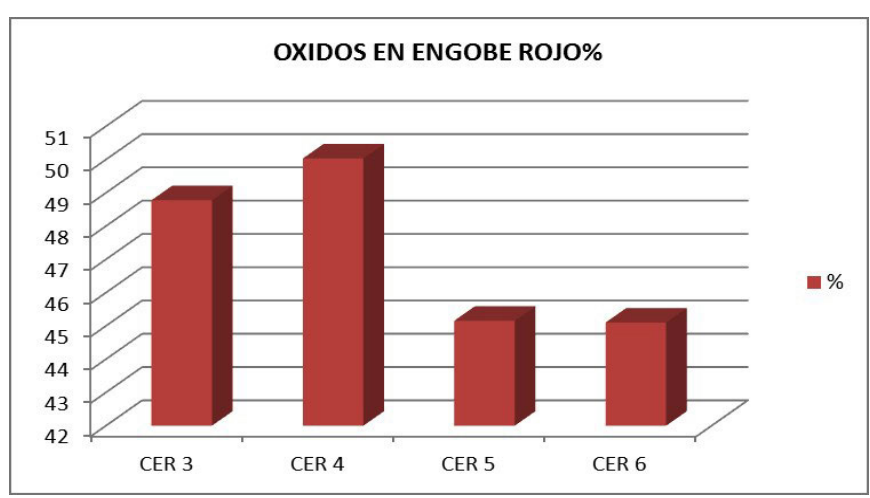

Gráfico $n^{0} 7$

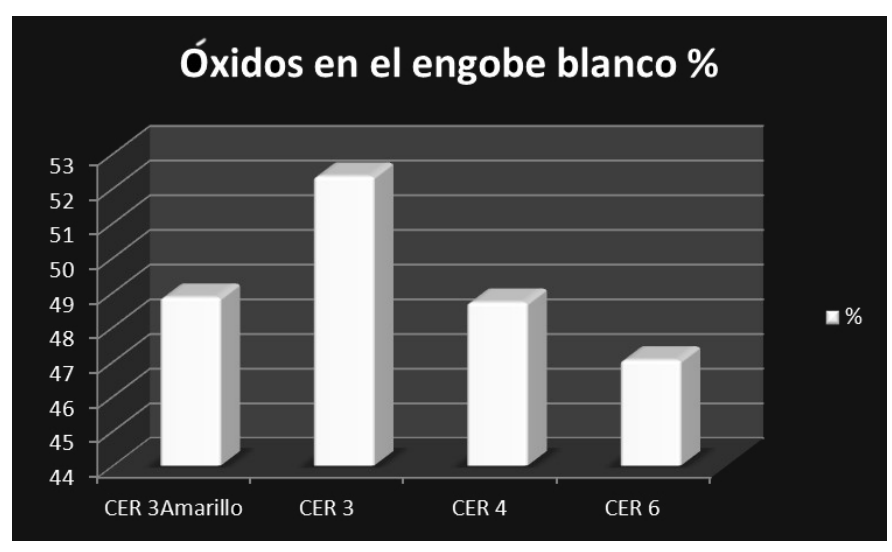

Tabla 4

\begin{tabular}{|l|c|}
\hline \multirow{2}{*}{$\begin{array}{c}\text { Engobes } \\
\text { negros }\end{array}$} & $\%$ \\
\cline { 2 - 2 } & Oxidos \\
\hline CER 1 & 51,8145478 \\
\hline CER 2 & 54,3890033 \\
\hline CER 3 & 50,2280956 \\
\hline CER 4 & 52,2580474 \\
\hline CER 5 & 66,8896313 \\
\hline CER 6 & 46,5489357 \\
\hline
\end{tabular}

Tabla 5

\begin{tabular}{|c|c|}
\hline Engob rojo & $\%$ \\
\hline CER 3 & 48,774847 \\
\hline CER 4 & 50,030575 \\
\hline CER 5 & 45,153616 \\
\hline CER 6 & 45,101234 \\
\hline
\end{tabular}

Tabla $n^{\circ} 6$

\begin{tabular}{|c|c|}
\hline Eng. Blanco & $\%$ \\
\hline CER 3 & 48,8585811 \\
\hline CER 3 & 52,34755353 \\
\hline CER 4 & 48,71327375 \\
\hline CER 6 & 47,048 \\
\hline
\end{tabular}




\section{DISCUSIÓN}

La diversidad iconográfica analizada en las muestras fragmentadas de cerámica provenientes del sitio de Markaconga es variada, porque parte desde una iconografía incisa con motivos geométricos en su superficie (M1 y M2), las secciones nos muestran que tuvo una cocción oxidante (M1). Luego la presencia de una variedad de técnicas de estampado, distingue característicamente y permite la identificación inequívoca de ser parte de los quemadores ceremoniales relacionados con Tiahuanaco Temprano del Cusco (Mohr, 1985).

Tomando como referencia lo manifestado por Mohr (1985), quien describe estos fragmentos de cerámica incisa, sellada y estampada como parte de formas de cabeza de felino inusuales, recogidos de superficie en sitios de Puno y Cusco, (véase el mapa de la ubicación de los sitios) en la que se incluye Pomacanchi, cuya descripción original se reporta en 1950 de dos piezas, recuperadas en Paruro por Jorge Pancorbo, alumno del Dr. Manuel Chávez Ballón; y otra que se encontró en Pikicallepata, durante las exploraciones en 1954 por el Dr. Manuel Chávez Ballón y el Dr. John H. Rowe, quienes comentaron sobre su rareza (figura 10).

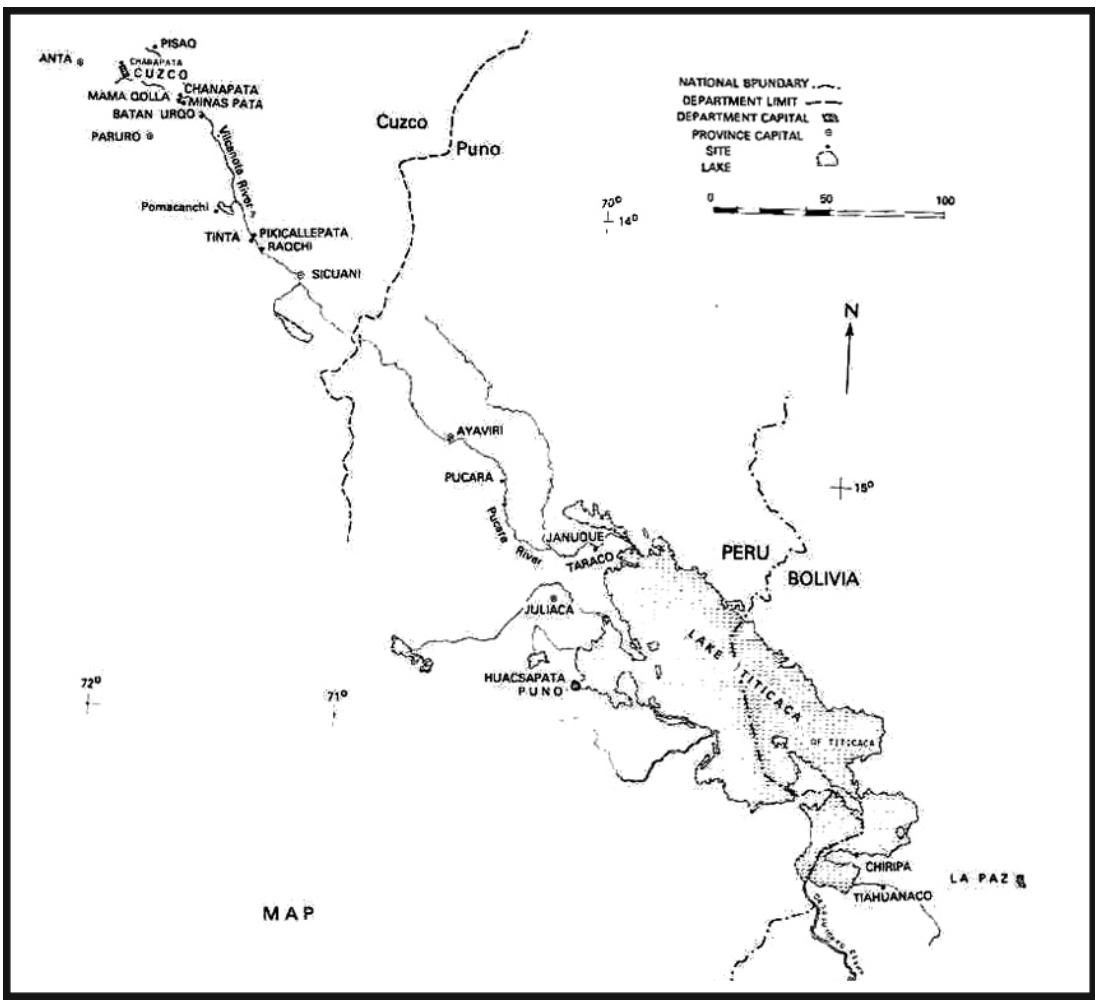

Figura 10: Mapa mostrando los sitios con presencia de este tipo de cerámica. Fuente: Karen Mohr (1985). 
La descripción de estos fragmentos de cerámica con elementos estampados felinos y cabezas modeladas, que sobresalen por encima de los bordes de los vasos son tan distintivos que han permitido a este pequeño, pero significativo grupo de tiestos, ser aislados, luego establece la unidad estilística del grupo y sostiene que los fragmentos procedían de los vasos ceremoniales de función especial que posee un felino manchado mitológico (otorongo). A su vez, estas piezas se comparan más de cerca en un número de maneras específicas para completar los quemadores ceremoniales de Bolivia que pertenecen al estilo Qeya (de Dwight T. Wallace), correspondiente a Tiahuanaco temprano de Wendell C. Bennett o Época III (de Carlos Ponce Sanginés). Debido a estas similitudes, el grupo de la cerámica sellada parece ser contemporáneo con el estilo temprano Tiahuanaco o Época III, que data de finales del período Intermedio Temprano, en algún momento quizá entre los siglos II y V d. C., se muestra la ocurrencia poco frecuente de quemadores ceremoniales para relacionarse con su función ritual única, aunque también es posible que simplemente hayan sido desconocidas. Sin embargo, la distribución de la cerámica estampada está muy extendida y casi continua a partir de Huacsapata posiblemente Chanapata, (segunda Fase de Marcavalle) con la mayor parte procedentes de Cusco.

Si bien el origen de quemadores ceremoniales aparece en la cuenca del lago Titicaca y se produce en la etapa pre-Pucara y el Tiahuanaco Temprano/Época III pre-Pucara, su propagación parece haber tenido lugar más tarde en los primeros tiempos Tiahuanaco/Época III, de la zona de Tiahuanaco hacia el norte en Cusco. Sin embargo, el grupo de cerámicas estampadas son lo suficientemente diferentes de los quemadores ceremoniales estilo Tiahuanaco Temprano, como para sugerir que no son importados directamente desde el lago Titicaca, sino que más bien se fabricaban en más de un lugar en la regiones de Cuzco y Puno, como la que se estaba dando posiblemente en la cuenca del lago Pomacanchi. Por otro lado, los grupos de cerámica con puntos estampadas, hasta principios de Tiahuanaco, son producto de una penetración religiosa (Yaya Mama) ${ }^{8}$ en Cusco durante el último período del Intermedio Temprano, antes de la incorporación de Cusco dentro del imperio Huari (Mohr, 1985).

El Fragmento M2: Muestra una oxidación incompleta de grano tosco y muy tosco con superficies incisas en la parte exterior y alisado tosco en la parte interna, que temporalmente podría ser considerado al igual que la muestra M1 (figura 11 y 12).

El estilo Qeya (100-600 d. C.): Según Jo Ellen Burkholder (2001) ${ }^{9}$, está hecha con pasta clara coloreada de valor alto y tono muy bajo, con colores desde 5YR (Marrón rojizo claro) hasta 2.5YR (Marrón rojizo oscuro). La cerámica es muy suave y apenas alcanza la consistencia de loza. Las inclusiones plásticas incluyen prominentes

8. Estas creencias religiosas y prácticas rituales compartidos, se hacen visibles en un estilo arquitectónico y artístico común unificado por primera vez los diversos pueblos que vivían alrededor del lago Titicaca. Este fenómeno cultural, que perduró durante siglos, hasta alrededor de 200-300 d. C., se llama la tradición religiosa Yaya-Mama según K. Chávez y S. Chávez (1997). 9. La Cerámica de Tiwanaku: ¿Qué Indica su Variabilidad? En Boletín de Arqueología Nº 5. Burkholder, Jo Ellen. (2001). 
lascas de mica o pirita. La decoración incluye elementos geométricos ejecutados en rojo, negro y algunas veces 7.5R amarillo rojizo, (Burkholder, 2001, p. 227 y Seddon 1998, p. 123) coinciden en ubicar el origen Qeya, en el formativo Tardío (1000 a 400 d. C.) pero este estilo continuo durante el periodo Tiwanaku IV Temprano (400-600 d. C.), e incluso quizá hasta el final del mismo. Geográficamente esta cerámica ha sido ubicada en todo el valle de Tiwanaku, Desaguadero, Batan Orqo y actualmente en Pomacanchi (ver figura 13 y 14).

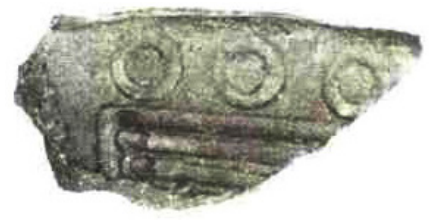

53

Figura 11. (53) Borde de muestras de tiestos de Pikicallepata.

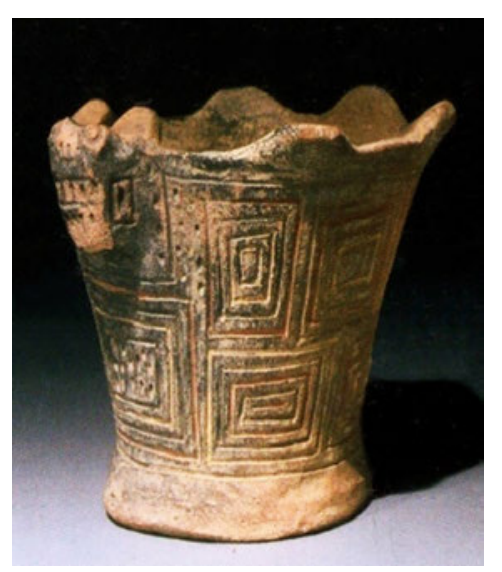

Figura 13. Quemador de incienso del estilo Qeya (300-500 d. C.) de Bolivia, cerámica modelada incisa, actualmente en Denver Art Museum. Gift of Gordon Deboard, 2002. 99

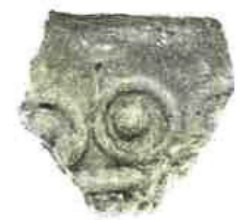

54

Figura 12. (54) Figura 54. Borde de muestras de tiestos de Batán 'Urqo .

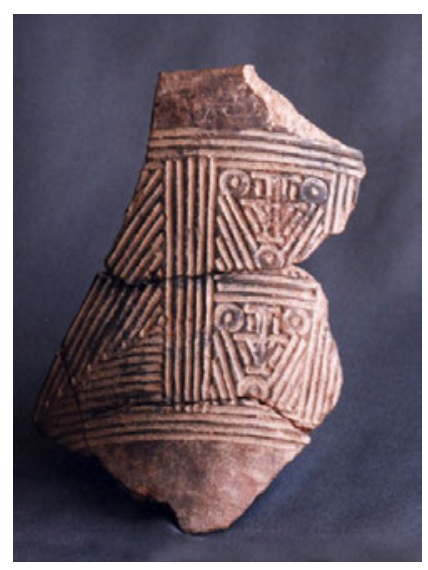

Figura 14. Fragmento de cerámica del estilo Qeya (tazón) con incisiones geométricas probablemente de Batan Orqo, ubicada por Chávez.

El fragmento M3: Nos muestra oxidación completa de grano mediano, su superficie esta alisada y bruñida por ambas caras en la superficie externa se desarrollaron engobe de color anaranjado sobre las que se desarrollaron líneas con engobe de color negro rebordeado con engobe de color blanco correspondiente a un vaso

El fragmento M4: Nos muestra la sección de cocción incompleta la superficie externa se halla con engobe de color rojo alisada y bruñida sobre las cuales se desarrollaron figuras escalonas con líneas de color negro rebordeadas con engobe de color blanco. Corresponde a la base de un vaso. 
El fragmento M5: Tiene la sección de oxidación completa, en la superficie alisada y bruñida el engobe es de color anaranjado sobre las que se desarrollaron líneas de engobe de color negro rebordeadas con engobe blanco corresponde al cuerpo de una vasija posiblemente globular.

Estos fragmentos analizados son de característica ceremonial, con una iconografía representativa de figuras escalonadas, que podría coligarse con el estilo Acarapi o Geométrico complejo (700-1000 d. C.). Según la descripción realizada por Jo Ellen Burkholder (2001), es el de mayor calidad dentro del corpus cerámico Tiwanaku, su pasta es de color rojo amarillento 5YR-Amarillo rojizo 7.5YR 7/6 a 6/8 con una consistencia dura como de piedra. Los antiplásticos tienden a ser pequeños y dispersos, las formas predominantes son los keros y los tazones, aunque puede haber otras formas (comparece con Alconini, 1995). Las superficies de este tipo de cerámica, están generalmente engobadas de rojo oscuro 10R 3/4-3/6, siempre son bruñidas o engobadas con mucho brillo. Las decoraciones consisten en signos escalonados, cruces, bandas de diamantes y círculos, luego elementos sólidos continuos como volutas y zigzags. A esto se incorporan las líneas rectas y onduladas que se parecen al estilo Chambi, los motivos son pintados directamente, sin delinear, el color blanco es añadido a menudo después de definir o resaltar círculos del fondo.

Este estilo es fechado desde mediados del periodo Tiwanaku IV Tardío hasta el final de Tiwanaku V Temprano, más o menos entre el 700-1000 d. C. Este tipo de decoración ha sido denominada como parte de los conjuntos "clásico" o "Tiwanaku IV", y es común su presencia en la parte sur de la cuenca del Titicaca, aunque también podría haberse expandido por la zona norte (corroboración mía en base a las observaciones de la cerámica analizada) (ver figura 15, 16 y 17).
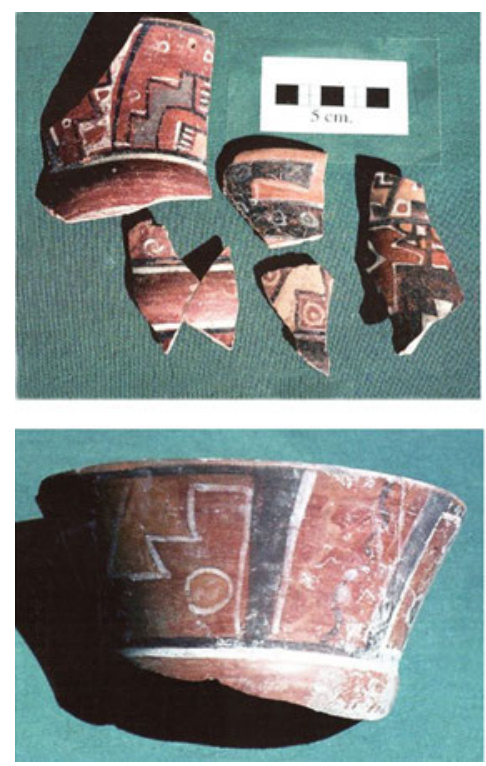

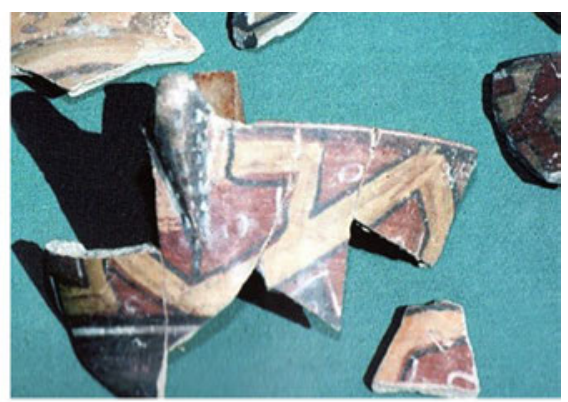

Figuras 15, 16 y 17. Muestras que corresponden al estilo Acarapi o Geométrico complejo, parte de un kero y varios fragmentos, con el cual hay un alto porcentaje de similitud de los fragmentos de cerámica analizados. Tomado de Burkholder (2001). 
El Fragmento M6: Muestra una sección de color gris correspondiente a una oxidación incompleta, se halla alisada y bruñida por las dos caras, en la cara externa se muestra la superficie con líneas de color blanco rebordeadas con líneas de color negro, además considera inclusiones de elementos malacológicos molidos e incorporados a la pasta cerámica, lo interesante de este fragmento es el uso de este elemento como mordiente, lo que expresaría que la manufactura de esta clase de cerámica era significativa e importante, y probablemente era importada que luego era ofrecida como parte de las ofrendas. Por otro lado en la zona alto andina se tiene un caracol blanco (C'huro): Polinices cf. Polinices uber. (Pozorski, 1979, p. 167) ha dado cuenta de su ocurrencia en Chan Chan; aunque con ínfima presencia, indica que se consumió al menos entre 1000 y 1450 d. C., en la costa norte. También fue comido en el sitio de Pacatnamú durante la ocupación Chan Chan, en la parte baja del valle de Jequetepeje (ver figura 18).

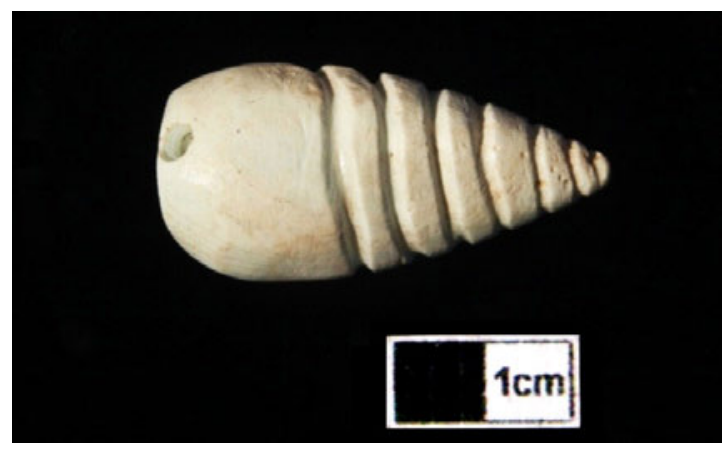

Figura 18. Muestra de una representación escultórica de un caracol al parecer terrestre, trabajada en base mineral (serpentina) de forma cónica con incisiones que van formando un cuerpo espiralado con un orificio en parte superior a manera de cuenta, utilizado en ceremonias de rituales. Hallada en el sector de Amaro Markawasi 2012 en Saqsayhuaman.

Este espécimen bien podría haber sido molido e incorporado a la pasta de la cerámica, sin embargo, al momento de la exposición a altas temperaturas, esta podría haberse incinerado por la poca dureza y consistencia, luego se tiene otras dos especies de conchas marinas que coexisten el Spondylus caacifer, que es grande y con el borde interno de color purpura rojizo, y Spondylus princeps, más pequeña, con el borde interior granate, las esculturas hechas en este material tienen mayor relevancia porque la concha es sagrada, además de que es uno de los objetos más intrigantes del antiguo Perú, y ser de importancia ritual en la región. Las primeras referencias sobre el uso del mullu y a tenor de los resultados arqueológicos, la presencia del Spondylus con uso ceremonial es fechable desde alrededor del 3200 a. C., en la cultura Valdivia del área costera ecuatoriana. Esta se registra en contextos rituales relacionados con la propiciación de lluvia. Esta asociación simbólica será una constante en la religiosidad andina.

Miguel Cabello de Balboa, Justo Modesto de Rubiños y Andrade recogen una leyenda mitológica sobre el origen del Reino Lambayeque, y uno de los elementos que llama especialmente la atención es el increíble cortejo. En él destaca el personaje del 
Fonga Sigde, capitán y acompañante de Naymlap, que tiene el curioso cometido de ir esparciendo polvo de Spondylus al paso del señor. Esto nos demuestra complejos rituales ligados al ejercicio de poder como símbolo de rango. De la existencia de este personaje del Fonga Sigde también se podría deducir un comercio institucionalizado de Spondylus (ver figura 19).

Para tener un panorama claro sobre el

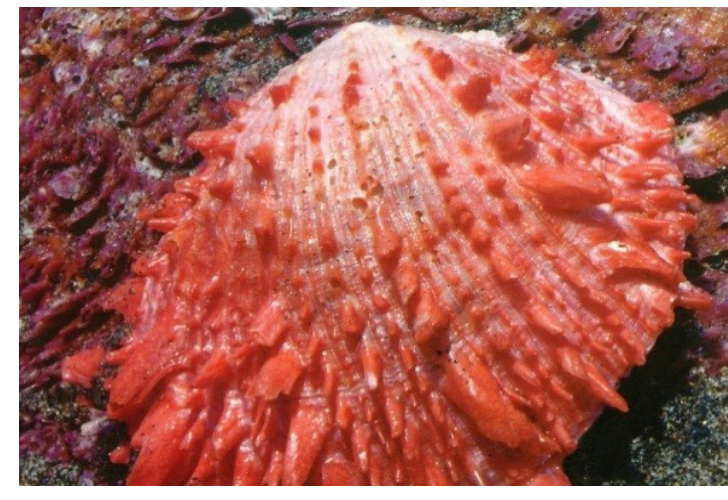

Figura 19. Concha Spondylus uso del spondylus en polvo como desgrasante en la cerámica de Markaconga, nos conduce a inferir que esta cerámica no es de manufactura local, ni corresponde temporalmente a las anteriores descritas, (Qeya y Tiwanaku) sino que es importada probablemente por los Wari, quienes tuvieron contacto con sociedades del norte costeño, que a su vez lo importaban de la costa ecuatoriana, por la importancia religiosa debió ser un signo de distinción social pues, porque aparece asociado a los enterramientos lujosos y haciendo de esta cerámica una pieza importante en su uso.

Lo que nos conlleva a sostener que este es un fragmento Wari, un estilo que fue identificado durante las excavaciones de Kullupata, que presenta diseños representativos de figuras geométricas y zoomorfas, realizados mediante líneas negras sobre fondo naranja, círculos concéntricos de color blanco o sobre fondo naranja rojiza. Los objetos representativos corresponden a cuencos, platos, jarras y vasos.

\section{NATURALEZA DE LA INVESTIGACIÓN}

Estuvo centrada en la fragmentería cerámica, cuyos recipientes cuando se encuentran completos generalmente suelen ser frágiles, mas no cuando se reducen a fragmentos. Con base en el análisis multielemental de estos y sus resultados, encausamos una interpretación preliminar sobre los primeros contactos tempranos de dos áreas importantes, la cuenca norte del lago Titicaca-Puno y Markaconga-Cusco. Luego nos propusimos afirmar o descartar, si entre las entidades tempranas y el Horizonte Medio se dieron variaciones estilísticas a través del intercambio o emulación de la cerámica, para esto revisamos exhaustivamente la literatura producida y el análisis del material procedente de este sitio.

Markaconga es casi único en exponer la presencia de una amplia muestra de cerámica decorada en estilos asociados tanto con la cultura Tiwanaku y Huari como significante. Hoy en día la relación social, económico y político entre estas culturas se mantiene en debate, tal como se da en Cerro Baúl en Moquegua. Por lo que tiene la potencia para aclarar estos temas con una estrategia adecuada. Una de las pre- 
guntas básicas por resolver es si las variaciones en el estilo, resultan de emulación (i.e., copias hechas apresuradamente) o si son productos de intercambio de bienes entre los pueblos de ambas culturas.

\section{Alcance e importancia de las contribuciones analíticas}

El alcance de la investigación contempló desde el Horizonte Temprano hasta el Horizonte Medio, la idea de los contactos tempranos entre las culturas del Titicaca y Cuzco, así como su influencia. Nuestra inferencia es que presumiblemente la cerámica haya sido introducida en el ámbito del Cuzco, antes de los marcavalle y que estos lograrían estar consolidándose como entidad compleja gracias a la introducción de la cerámica altiplánica o circumlacustre.

Sobre las contribuciones analíticas podemos manifestar que la presente investigación se basa en la sistematización de resultados del análisis químico por fluorescencia de rayos $\mathrm{X}$ de pastas y pigmentos de cerámica o multielementales, realizada a fragmentos de cerámica de superficie (06 muestras) en el año 2013, nos muestran un corpus iconográfico Pukara, Qeya, Tiwanaku, Wari y estilos locales (Marcavalle y Chanapata). Estos estudios piloto fueron diseñados para averiguar si un análisis multielemental utilizando cortes de secciones delgadas son suficientes para identificar las diferencias entre intercambio y emulación de cerámica.

Logramos confirmar con el resultado, la existencia de un contacto importante entre las culturas tempranas del Titicaca y Cuzco, que continuó en el Intermedio Temprano como un nódulo de interacción entre el altiplano Tiwanaku y culturas locales, y que para el Horizonte medio se consolida y se convierte en una frontera de interacción entre culturas locales, tiwanakus y huaris.

Según nuestra observación y análisis presumimos que la cerámica ha sido introducida en el ámbito del Cuzco, antes de los marcavalle, y que estos lograrían su consolidación como entidad compleja, gracias a la introducción de la cerámica altiplánica o circumlacustre, la cual requiere mayores datos.

Metodológicamente utilizamos los cortes delgados enfocados sobre algunos rasgos que pudieran reflejar diferencias de materiales naturales utilizado en la manufactura de cerámica (i.e., la mineralogía de inclusiones no-plásticas) así como diferencias tecnológicas (e.g., composición de pigmentos, preparación de inclusiones, etc.) en el caso que estos estudios piloto nos confirmen la potencia de estas técnicas.

Para una segunda etapa nuestra intención es iniciar otro estudio con una muestra más grande y una metodología de muestreo más sistemático y sofisticado que confirme o descarte nuestras ideas.

Por las razones que ya mencionamos, el estudio ha sido un éxito y hemos demostrado que, si podemos distinguir la composición de fragmentos de cerámica por fuera y por dentro, por lo tanto, parece que el intercambio de bienes está ocu- 
rriendo en Markaconga. Sin embargo, se necesita un estudio mayor y mejor para caracterizarlo y entenderlo.

\section{CONCLUSIONES}

La variedad petrográfica nos indica que, si hubo relaciones con la cuenca norte del Titicaca, desde periodos muy tempranos, porque en Sicuani, Calero y Fernández $(2015)^{10}$ manifiestan haber registrado fragmentos de cerámica del estilo Qaluyo, que son foráneos y relacionados con la que aparece en Ayaviri (Qaqachupa-Puno). Entonces podría inferirse tentativamente que estas relaciones ya se venían dando desde el Horizonte Temprano, no solo con Qaluyo Temprano, sino con Chiripa Temprano, quienes compartían similitudes tipológicas, morfologías y artísticas. Si esta situación se venía dando para el área de Sicuani, es comprensible inferir que para la zona de Pomacanchi, también se pueda estar dando este fenómeno, con la aclaración que las rutas de relaciones, contactos y/o migraciones son varias. No solo a través de la vía del abra de la Raya, sino que también tenemos bifurcaciones que parten desde Ayaviri, Llalli en territorio puneño para continuar con Sutunta, Mullocahua, Pichigua, Descanso, Canas, circuito de Cuatro Lagunas, hasta Pomacanchi en territorio cusqueño.

Refuerza nuestra idea que la influencia altiplánica en Pomacanchi, es más notoria con la cuenca norte del lago Titicaca, por la presencia de cerámica con iconografía Pukara y luego a miembros de la Tradición Religiosa Yaya-Mama, propuesta por Sergio Chávez (2002), quienes tienen patrones estilísticos y artísticos muy identificables en su alfarería.

\section{En cuanto a los análisis multielementales podemos observar lo siguiente:}

1. De estos exámenes extrínsecos de carácter decorativo, nos muestran que existen diferencias compositivas distintas entre sí y que podrían estar refiriéndose a estilos y/o procedencias distintas.

2. El análisis granulométrico realizado en el tamaño de grano de los antiplásticos o inclusiones no plásticas, muestran que los fragmentos M1 y M2 tienen inclusiones plásticas angulosas toscas y muy toscas, mientras que los siguientes fragmentos (M3 grano medio y los fragmentos M4, M5 y M6) tienen inclusiones plásticas que van desde granos finos y muy finos de acuerdo a la clasificación de Wentworth.

3. Los análisis petrográficos nos indican que los fragmentos M1 y M2 tienen inclusiones no plásticas cuarcitas policristalinas; mientras que los fragmentos M3, M4 y

10. Excavaciones en la Comunidad Campesina de Chumo, en: Calero y Fernández (2015). Arqueología de los períodos alfareros tempranos del distrito de Sicuani-Cusco (pp. 889-892.). Tesis presentada, para optar al título profesional de licenciados en Arqueología. UNSAAC, Facultad de Ciencias Sociales, Departamento Académico de Arqueología. 
M5 tienen inclusiones no plásticas del tipo félsico y máfico que nos permite plantear que, estos fragmentos fueron manufacturados sobre la base de una misma práctica o tradición tecnológica, la M6 tiene inclusiones de elementos malacológicos molidos que marcan la diferencia.

4. Los análisis composicionales de las pastas nos muestran diferencias entre los fragmentos M1, M2, M3 y M4 y similitudes composicionales entre los fragmentos M5 y M6.

5. Los análisis correlacionales a nivel de elementos de traza y la presencia de rubidio y estroncio permite distinguir probables procedencias de fuentes de materia prima para la elaboración de los ceramios, esto nos indica que, los fragmentos M3 y M4 estarían utilizando la misma fuente de materia prima mientras que las demás muestras tendrían fuentes de materia prima distintas.

La correlación en el uso de las materias pigmentarias utilizadas para la manufactura de los engobes nos india lo siguiente:

1. Los óxidos negros utilizado para decorar la superficie de las muestras M1 y M2 son las mismas, así como los fragmentos M3 y M4 utilizarían la misma fuente mientras que los engobes negros de las muestras M5 y M6 son distintos entre sí.

2. La Utilización de los engobes rojos (M3 y M4) son distintos entre sí, y los engobes anaranjados serian engobes similares. El Uso de engobes Blancos o amarillentos tendría cierta relación entre los engobes M3 y M4.

Finalmente, las interrogantes que nos planteamos al inicio del presente estudio, estarían dando respuesta a partir de los distintos análisis particulares de: pastas, petrografía, mineralogía composicional por FRX llevados a cabo:

- ¿Son las diferencias composicionales y cromáticas, probables indicadores que permitan evidenciar diferencias en la manufactura?; Evidentemente que sí, porque se están dando diferencias composicionales en las pastas cerámicas, así como en la correlación del uso de los materiales pigmentarios utilizados en la manufactura de los engobes.

- ¿Son los estilos iconográficos, elementos que permiten diferenciar las procedencias de dichos artefactos? Claro que sí, el mismo que, puede ser corroborado o descartado a través de los análisis multielementales o petrografía de la cerámica.

- ¿Es Markaconga el lugar de confluencia de distintos grupos étnicos en distintos Periodos de confluencia? La distinción iconográfica nos muestra que, si existen diversidad y similitud de Estilos cerámicos de los grupos étnicos que convergieron en el lugar de estudio. 
Agradecimientos: A Richard Burger, Lucy Salazar y Thomas Fenn, (Universidad de Yale) por organizar y coordinar el I Curso. Su paciencia al introducirnos al mundo de la petrografía siempre será rememorada.

A mi alumno Frankmerced Emerson Farfán Huanca, que nos ofreció las muestras cuyas raíces indican ser de Markaconga.

\section{REFERENCIAS BIBLIOGRÁFICAS}

Burkholder, Jo E. (2001). La Cerámica de Tiwanaku: ¿Qué Indica su Variabilidad? En Boletín de Arqueología PUCP, 5, pp. 217-249.

Calero Flores, J. y Fernández Palomino, M. (2015) Arqueología de los períodos alfareros tempranos del distrito de Sicuani-Cusco. Tesis presentada, para optar al título profesional de licenciados en arqueología. UNSAAC. Facultad de Ciencias Sociales, Departamento Académico de Arqueología (pp. 889-892.).

Chávez, S. J. (2004). The Yaya-Mama Religious Tradition as an Antecedent of Tiwanaku. Tiwanaku Ancestors of the Inka. Denver Art Museum, University of Nebraska Press, Lincoln and London. pp. 71-75.

Chávez, S. J. (2002). Identification of the Camelid Woman and Feline Man Themes, Motifs, and Designs in Pucara Style Pottery. Andean Archaeology II, Art, Landscape, and Society. Chapter 2. Kluwer Academic/Plenum Publishers. New York, Boston, Dordrecht, London, Moscow. pp.37-38.

Chávez, S. J. (1988). Archaeological Reconnaissance in the Province of Chumbivilcas, South Highland Peru" Expedition, 30(3), 27-38

Díaz de Liaño del Valle, G. (2012). Cuando Los Objetos Juegan un Papel en la Sociedad: Introducción a la Arqueología Simétrica. 3er "Curso del grado de arqueológica UCM. ARQUEO UCA, 2, 139-149.

Druc, I. y Chávez, L. (2014). Pastas Cerámicas en Lupa Digital: Componentes, Textura y Tecnología, Deep University Press, Blue Mounds, Wisconsin.

Gonzales Ruibal, A. (2007). Arqueología simétrica: un giro teórico sin revolución paradigmática, Complutum, 18, pp. 283-286.

Gosselain, O. y Livingstone-Smith, A. (2005). The source clay selection and processing practices in Sub-Sahara Africa. En A. Smith, D. Bosquet y R. Martineau, (Ed.). Pottery Manufacturing Process: Reconstitution and Interpretation (pp. 3347). BAR International Series 1359, Oxford.

Hodder, I. (2004). Archaeology beyond Dialogue, The University of Utah Press. (pp. 6992). Salt Lake City.

Kuhn, T. (2006). La estructura de las revoluciones científicas, Fondo de Cultura Económica, México. 
Mohr Chávez, K. (1985). Early Tiahuanaco-Related ceremonial burners from Cuzco, Peru. Dialogo Andino $N^{\circ}$ 4. Departamento de Historia y Geografía. Universidad de Tarapacá, Arica Chile.

Moro Abadía, O. (2007). La 'arqueología simétrica' o la irrupción de la sociología del conocimiento científico en arqueología, Complutum, 8, pp. 318-319.

Pozorski, S. (1979). Prehistoric Diet and Subsistence of the Moche Valley, Peru. En: Wold Archaeology, 11(2), 163-184.

Lechtman, H. (1977). Style in technology.Some early thoughts. En H. Lechtman y R. Merill (Ed.). Material Culture, Styles, Organizations, and Dynamics of Technology, (pp. 3-20).

Lemonnier, P. (1992). Elements of an Anthropology of Technology. University of Michigan, Ann Arbor.

López Cuevas, F. (2005). El Spondylus en el Perú prehispánico. Su significación religiosa y económica. En ÁMBITOS, Revista de Estudios de Ciencias Sociales y Humanidades, 14, pp. 33-42. Universidad de Córdoba.

Lull Santiago, V. (1988). Hacia una teoría de la representación en Arqueología. Revista de Occidente, 81, pp. 62-76.

Ottalagano, Flavia V. (2015) Explorando la Variabilidad Petrográfica entre Vasijas Decoradas y Lisas del Sitio La Palmera 2 (Entre Ríos, Argentina): Hacia un Abordaje Microscópico del Arte Cerámico Prehispánico de la Cuenca del Río. Revista Chilena de Antropología 32(2), (pp. 21-38).

Ramón Joffre, G. (2013). Los Alfareros Golondrinos. Productores Itinerantes en los Andes, Instituto Francés de Estudios Andinos (UMIFRE 17, CNRS-MAE)

Sackett, J. (1993). Style and ethnicity in archaeology: the case for isichrestism. En: New Directions in Archaeology. The uses of style in archaeology. Edited by M. Conkey and Ch. Hastorf, (pp. 32-43). Cambridge University Press.

Sackett, J. (1985). Style, ethnicity and stone tools. En R. Thomson, M. García y F. Kense (Eds.). Status, Structure an Stratification: Current Archaeological Reconstructions, (pp. 277-282). University of Calgary, Calgary.

Skibo, J. (2013). Understanding Pottery Function.Springer, NewYork-Heidelberg.

Schiffer, M. y J. Skibo. (1987). Theory and experiment in the study of technological change. Current Antropology, 28(5), 595-621.

Schiffer, M. y Skibo, J. (1997). The explanation of artifact variability. American Antiquity, 62(1), 27-50.

Wentworth, C. K. (1922). A scale of grade and class terms for clastic sediments. Journal of Geology, 30, pp. 377-392. 


\section{SOBRE LOS AUTORES}

\section{Wilber Bolívar Yapura}

Arqueólogo egresado de la Universidad Nacional de San Antonio Abad del Cusco, Magíster en Gestión del Patrimonio Cultural por la Universidad Nacional Mayor de San Marcos, Candidato a Doctor en Ciencias Sociales, Gestión Pública y Desarrollo Territorial por la Universidad Nacional del Altiplano-Puno. Es docente en la Escuela Profesional de Arqueología UNSAAC. Miembro de Instituciones como del Centro Internacional de Monumentos y Sitios (ICOMOS), ex-Decano Nacional del Colegio Profesional de Arqueólogos del Perú. Ha publicado varios artículos en revistas indexadas con temática sobre montañas sagradas, caminos prehispánicos a los otros Cuscos, la muerte, Amazonía, arte rupestre, Centro Histórico del Cusco, etc.

Codirector y coeditor de las Revistas de Arqueología Peruana del COARPE, Números 1 y 2. Ha brindado conferencias a nivel nacional en ciudades como Lima, Ayacucho, Huaraz, Cusco y Puno, y en países como México: ciudades de Pachuca de Soto Hidalgo y México DF., y en Bolivia: ciudades del Alto y La Paz).

\section{Gladys Lagos Aedo ( $†$ )}

Estudios en maestría de Gestión del Patrimonio Cultural y Centros Históricos. UNSAAC. Grado académico de Doctora, con estudios concluidos en la Universidad Del País Vasco/Euskal Herriko Unibertsitatea, Europa, especialidad en Sociedad Democrática Estado y Derecho. Doctoranda de la Universidad Católica Santa María de Arequipa, grado en Ciencias Sociales, grado académico de magíster en Administración de Empresas, título profesional de Arqueóloga y grado de Bachiller en Arqueología y varios estudios de maestría en: Investigación Tecnología y Desarrollo; Gestión del Patrimonio Cultural y estudios de posgrado referidos al Patrimonio Cultural de la Nación, Tecnologías Educativas, Metodología de la Investigación Científica y con competencia en trabajos de Investigaciones Arqueológicas en costa sierra y selva, particularmente en Arqueología de Alta Montaña, ponente en diferentes eventos académicos referidos a investigaciones arqueológicas y temas del patrimonio cultural.

\section{Jorge Luis Gamarra Gamio}

Ingeniero Químico por la Universidad San Antonio Abad del Cusco, con estudios de segunda especialidad en conservación y restauración de bienes culturales muebles e inmuebles por la misma casa de estudios. Actualmente trabaja para la Dirección Desconcentrada de Cultura de Cusco. 